\title{
Health-Related Quality of Life and its contributory factors in Allergic rhinitis patients in Nigeria
}

Stephen Oluwatosin ADEBOLA ${ }^{1}$, FWACS; Babatunde ABIDOYE ${ }^{2}$, PhD;

Foluwasayo Emmanuel OLOGE ${ }^{3}$, FWACS; Oyebola Eyitayo ADEBOLA ${ }^{4}$, MBBS; Benjamin Agboola OYEJOLA ${ }^{5}$, PhD.

${ }^{1}$ Department of Otorhinolaryngology, Ladoke Akintola University of Technology (LAUTECH) Teaching Hospital, Ogbomoso, Nigeria.

${ }^{2}$ Centre for Environmental Economics and Policy in Africa (CEEPA), Department of Agricultural Economics, Extension and Rural development, University of Pretoria, Pretoria, South Africa.

${ }^{3}$ Department of Otorhinolaryngology; University of Ilorin Teaching Hospital, \& College of Health Sciences, University of Ilorin, Ilorin,, Nigeria.

${ }^{4}$ Department of Epidemiology and Community Health, University of Ilorin Teaching Hospital, Ilorin, Nigeria.

${ }^{5}$ Department of Statistics, University of Ilorin, Ilorin, Nigeria.

Key words. Allergic Rhinitis, Health-Related Quality of Life (HRQoL), Nigeria.

\section{Correspondence:}

Dr. Stephen O Adebola,

Consultant Otorhinolaryngologist,

Ladoke Akintola University of Technology (LAUTECH) Teaching Hospital,

Ogbomoso, NIGERIA.

E-mail: tosinadebolang@yahoo.com

Phone No: +2348130721916

Postal Address: GPO Box 4916, Ilorin, Kwara state, NIGERIA, 240001. 


\section{Abstract \\ Objectives}

To determine the health-related quality of life (HRQoL) in allergic rhinitis patients as well as identify contributory factors to patient's well-being.

\section{Methods}

Cross sectional study by multistage sampling. Four month study duration (October, 2013 to January, 2014). The setting of study was Kwara state, Nigeria which has 16 Local Government areas with 3 senatorial districts, total land mass of $36,825 \mathrm{~km}^{2}$ with population of 2,591,555. 132 consenting adults; 66 of them have allergic rhinitis (AR) using Score for Allergic Rhinitis (SFAR) instrument and 66 were age and gender matched controls. $\left(\chi^{2}=0\right.$, d.f. $=1, \mathrm{P}=1$ and $\chi^{2}=1.24$, d.f. $=2, \mathrm{P}=0.54$ respectively). Information on HRQoL was obtained using the 14-parameter mini Rhinoconjuctivitis quality of life questionnaire (miniRQLQ). Socio-demographic variables possibly contributory to patient's well-being were obtained. Kruskal- Wallis and Mann-Whitney U tests were used to compare means.

\section{Results.}

The overall Total Symptom Score (TSS) was $3.37 \pm 0.9$, while male and female allergic patients and control TSS were $3.61 \pm 1.0 ; 3.16 \pm 0.8$, and $0.98 \pm 0.2 ; 0.95 \pm 0.2$ respectively. Effects of gender, marital status, senatorial districts, residential area and duration of symptoms had significant impact on the quality of life. The highest correlation with TSS and components of mini-RQOL questionnaire existed between nasal problems and other symptoms $(r=0.866 ; 0.868)$.

\section{Conclusion.}

AR had appreciable impact on HRQoL of the participants. Gender, number of dependents, marital status, senatorial districts, residential area and duration of symptoms were major identifiable contributory factors to the patient's well-being.

Key words. Allergic Rhinitis, Health-Related Quality of Life (HRQoL), Nigeria. 


\section{Introduction}

Allergic rhinitis refers to a chronic clinical condition which involves inflammation of the nose and paranasal sinuses. While worldwide prevalence is varied, a recent hospital based study done in North-Central Nigeria reported $31.6 \% .{ }^{1}$ Despite the availability of medications to control the disease and thus minimize the morbidity, misdiagnosis and underdiagnosis of the condition still arises leading to an undermining of the severity of the impact of the disease.

It becomes important therefore to determine the severity of the disease using Patient-reported Treatment Outcomes (PTO), which are based on the perception of the disease by the recipients. This fact has been identified by the World Health Organization (WHO) sponsored document, Allergic Rhinitis and its Impact on Allergy (ARIA). ${ }^{2}$ The single most important aspect is the Health-Related Quality of life (HRQoL). This relates to the overall quality of life which has been shown to affect healthcare. ${ }^{3}$ It refers to a broad concept which is based on the patient's subjective assessment of the impact of the disease or the treatment being received on account of the disease. ${ }^{4}$

The instruments used to obtain HRQoL information, can either be generic or disease-specific in nature. ${ }^{5}$ The generic instruments are designed to be used for patients with general health states, thus comparison is often easier. Such examples include Medical Outcomes Survey Short Form 36 (SF-36), ${ }^{6}$ Nottingham Health profile (NHP). ${ }^{7}$ Despite the advantages, the major drawback of the generic instruments is the inability to measure specific peculiarities inherent in each disease. The other type of instrument is the disease specific instrument. These are designed to address the deficiencies noted in the generic instruments and thus tend to be more sensitive to changes in patient's symptoms. An example of this is the MiniRhinoconjuctivitis Quality of life questionnaire (mini-RQLQ) ${ }^{8}$ which is a 14-item instrument which has strong measurement properties and measures the same construct as the original 28item Rhinoconjuctivitis Quality of life questionnaire (RQLQ). ${ }^{9}$

Kwara state is located within the North-Central geopolitical zone of Nigeria, one of the six zones in the country. The state has 16 Local Government areas with 3 senatorial districts, a total land mass of $36,825 \mathrm{~km}^{2}$ with a population of $2,591,555^{10}$. The senatorial districts are namely; Kwara Central, Kwara South and Kwara North. Each of the districts has its own individual peculiarities. The most affluent of these is the Kwara Central, where the state capital is located and largest concentration of healthcare facilities are sited. 
The study aims at determining the health-related quality of life (HRQoL) in allergic rhinitis patients in our study population and identify contributory factors to patient's well-being in both rural and urban communities in Kwara state, Nigeria.

\section{Materials and Methods}

Study Design: The study was a community based cross sectional study carried out in selected local government areas (LGAs) in Kwara state, Nigeria. Ethical approval was sought and obtained from the Ethics committee of the Ministry of Health, Kwara state prior to the commencement of the study. The study was over a 4 month period (October, 2013 to January, 2014).

The inclusion criteria for the study were; adults $>18$ years of age who were diagnosed with allergic rhinitis using Score For Allergic Rhinitis (SFAR), a validated instrument for making a diagnosis of allergic rhinitis, based on the study of Annesi-Maesano et al. ${ }^{11}$ This involved the use of parameters such as nature of symptoms, presence of Rhinoconjuctivitis, presence of trigger factors, months of the year affected, perceived allergic status, previous medical diagnosis of allergy, previous positive tests and family history of allergy. Each of these parameters have attributed weighted scores which add up to a maximum score of 16. A diagnosis of allergic rhinitis is based on a score of $\geq 8$, while $<8$ is diagnosed non allergic. The study group were matched for age and sex by selecting respondents who were $>18$ years but diagnosed non allergic based on SFAR. These formed the control group. Participants who were $>18$ years of age and failed to give signed informed consent were excluded from the study. The sample size was derived using the Fishers formula. ${ }^{1}$

Sampling technique was carried out in four stages using multistage sampling technique. In stage one, nine of the sixteen local government areas in Kwara state were chosen by simple random sampling using simple balloting. In stage two, 2 communities were chosen from each of the nine selected LGAs, by simple random sampling using the table of random numbers. In stage three, proportionate allocation was used to allocate the proportion of households that will be sampled in each (of the eighteen) community chosen based on the population of households in the community. In stage four, systematic sampling was used to determine the sampling interval for the houses in the communities sampled.

In each household visited, every first adult (aged $>18$ years) met was approached and the study (including the purpose, scope, possible benefits and associated risks) was explained to 
the subject. Informed consent was obtained from subjects. When there was a decline, the next eligible adult in the same household was approached.

A total of 66 participants were diagnosed to have allergic rhinitis out of the 289 respondents sampled. These formed the group 1. They were matched for age and sex from the rest of the respondents who had no allergic rhinitis, and 66 controls were obtained (also from the rest of the 289 respondents). These formed group 2.

Research Instruments: Data were generated from information obtained from the participants using two major instruments by the researchers. The first instrument included the Score for Allergic Rhinitis (SFAR), a validated instrument for making a diagnosis of allergic rhinitis, based on Annesi-Maesano et al, ${ }^{11}$ (Appendix 1) together with other socio-demographic characteristics. The other instrument used was the Mini-Rhinoconjuctivitis Quality of Life questionnaire (mini-RQLQ) (Appendix 2). This instrument involves fourteen items which are grouped into five sub-groups, namely; activity limitation, practical problems, nasal symptoms, eye symptoms and other symptoms. The overall classification was recorded as Total Symptom Score (TSS).

Data was collated and analysed using SPSS statistical package (version 18, Chicago, Il). Differences between categorical variables were explored using the Chi- square test, while Kruskal-Wallis and Mann Whitney U tests were used to test the significance of the various possible contributory factors associated with well-being in allergic rhinitis patients. All analyses were done with statistical significant level of $\alpha=0.05$.

\section{Results}

A total of 132 adult participants were seen during the study period. Sixty six of these were diagnosed to have allergic rhinitis, (AR) using the Score for Allergic Rhinitis (SFAR) instrument and 66 were age and gender matched controls $\left(\chi^{2}=0\right.$, d.f. $=1, P=1$ and $\chi^{2}=1.24$, d.f. $=2, P=0.54$ respectively). The number of males and females in each group were 30 and 36 respectively. The mean age of the participants was also similar; $37.6 \pm 10.0$ (Allergic) and $35.5 \pm 9.1$ (Non-Allergic). Total Symptom Score (TSS) for allergic patients using the miniRQLQ questionnaire was $3.37 \pm 0.9$ with a value of $3.61 \pm 1.0$ for male and $3.16 \pm 0.8$ for female while for the non-allergic, the values were $0.98 \pm 0.2$ (males) and $0.95 \pm 0.2$ (females) (Table1). 
Table 1; Socio-demographic Characteristics of the Participants.

\section{Parameter}

Allergic Participants

Non-Allergic

Participants

\section{Gender of} participants

Male

$30(45.5)$

$30(45.5)$

Female

$36(54.5)$

$36(54.5)$

Age range (years)

$20-29$

$20(30.3)$

$21(31.8)$

$0.144(0.986)$

$30-39$

$20(30.3)$

21 (31.8)

$40-49$

$22(33.3)$

$20(30.3)$

$50-59$

4 (6.1)

4 (6.1)

Mean \pm SD

$37.6 \pm 10.0$

$35.5 \pm 9.1$

Marital status

Single

Married

Widowed

LGA grouping

according to

Senatorial districts

Kwara central

$20(30.2)$

$22(33.3)$

24 (36.5)

Kwara north

$60(90.9)$

$0(0)$

Kwara south
$8(12.1)$

$54(81.8)$

$4(6.1)$

$4.602(0.100)$

Total symptom

scores (TSS)

Male

$3.61 \pm 1.0$

$0.98 \pm 0.2$

Female

$3.16 \pm 0.8$

$0.95 \pm 0.2$

$22(33.3)$

$0.182(0.913)$

$22(33.3)$

$22(33.4)$

\section{$*$ significant $\mathrm{p}$-value $(\mathrm{p}<0.05)$}


Table 2: Levels of Quality of Life of Allergic Patients by the Components of the Mini Rhinoconjuctivitis (mRQOL) Questionnaire Sub-group

\begin{tabular}{|c|c|c|c|c|c|c|}
\hline Levels & $\begin{array}{l}\text { Activity } \\
\text { limitation } \\
\mathrm{n}=66(\%)\end{array}$ & $\begin{array}{l}\text { Practical } \\
\text { problems } \\
n=66 \\
(\%)\end{array}$ & $\begin{array}{l}\text { Nose } \\
\text { symptoms } \\
\text { n=66 (\%) }\end{array}$ & $\begin{array}{l}\text { Eye } \\
\text { symptoms } \\
\text { n=66 (\%) }\end{array}$ & $\begin{array}{l}\text { Other } \\
\text { symptoms } \\
\text { n=66 }(\%)\end{array}$ & $\begin{array}{l}\text { Total } \\
\text { score } \\
\text { n=66 }(\%)\end{array}$ \\
\hline $\begin{array}{l}\mathbf{0}-1.0 \\
\text { (Not } \\
\text { troubled) }\end{array}$ & $4(6.1)$ & $0(0.0)$ & $0(0.0)$ & $2(3.0)$ & $0(0.0)$ & $0(0.0)$ \\
\hline $\begin{array}{l}\text { 1.1-2.0 } \\
\text { (Hardly } \\
\text { troubled) }\end{array}$ & $8(12.1)$ & $4(6.1)$ & $6(9.1)$ & $10(15.2)$ & $22(33.3)$ & $4(6.1)$ \\
\hline $\begin{array}{l}2.1-3.0 \\
\text { (Somewhat } \\
\text { troubled) }\end{array}$ & $20(30.3)$ & $26(39.4)$ & $16(24.2)$ & $26(39.2)$ & $22(33.3)$ & $16(24.2)$ \\
\hline $\begin{array}{l}\text { 3.1-4.0 } \\
\text { (Moderately } \\
\text { troubled) }\end{array}$ & $8(12.1)$ & $16(24.2)$ & $24(36.4)$ & $16(24.2)$ & $8(12.1)$ & $32(48.5)$ \\
\hline $\begin{array}{l}\text { 4.1-5.0 } \\
\text { (Quite a bit } \\
\text { troubled) }\end{array}$ & $18(27.3)$ & $8(12.1)$ & $16(24.2)$ & $12(18.2)$ & $12(18.2)$ & $14(21.2)$ \\
\hline $\begin{array}{l}5.1-6.0 \\
\text { (Very } \\
\text { troubled) }\end{array}$ & $8(12.1)$ & $12(18.2)$ & $4(6.1)$ & $0(0.0)$ & $2(3.0)$ & $0(0.0)$ \\
\hline $\begin{array}{l}\text { Overall score } \\
( \pm \text { SD) }\end{array}$ & $3.5(1.4)$ & $3.8(1.3)$ & $3.7(1.1)$ & $3.1(1.1)$ & $2.9(1.2)$ & $3.37(0.9)$ \\
\hline
\end{tabular}


Table 3: Significance of the Various Contributory Factors on the Components of the Mini Rhinoconjuctivitis Questionnaire Sub-group

\begin{tabular}{|c|c|c|c|c|c|c|}
\hline Factors & $\begin{array}{l}\text { Activity } \\
\text { limitation } \\
\text { (p value) }\end{array}$ & $\begin{array}{l}\text { Practical } \\
\text { problems } \\
\text { (p value) }\end{array}$ & $\begin{array}{l}\text { Nose } \\
\text { symptoms } \\
\text { (p value) }\end{array}$ & $\begin{array}{l}\text { Eye } \\
\text { symptoms } \\
\text { (p value) }\end{array}$ & $\begin{array}{l}\text { Other } \\
\text { symptoms } \\
\text { (p value) }\end{array}$ & $\begin{array}{l}\text { Total } \\
\text { score } \\
\text { (p } \\
\text { value) }\end{array}$ \\
\hline Age & $0.014 *$ & 0.986 & 0.136 & 0.810 & 0.048 & 0.215 \\
\hline Gender & 0.531 & $0.003 *$ & 0.601 & 0.378 & $0.001^{*}$ & $0.016^{*}$ \\
\hline Marital status & $0.049^{*}$ & 0.319 & 0.024 & 0.388 & $0.001 *$ & $0.016^{*}$ \\
\hline Educational status & 0.109 & 0.475 & $0.024 *$ & 0.071 & 0.275 & 0.096 \\
\hline $\begin{array}{l}\text { Number of } \\
\text { dependents }\end{array}$ & $0.001 *$ & 0.359 & 0.073 & 0.447 & $0.043^{*}$ & $0.012 *$ \\
\hline $\begin{array}{l}\text { LGA Groups - } \\
\text { Senatorial District }\end{array}$ & $0.005^{*}$ & $<0.001^{*}$ & $0.006^{*}$ & $0.007 *$ & $0.003 *$ & $0.001 *$ \\
\hline Residential area & 0.087 & $0.001 *$ & $<0.001 *$ & $0.007^{*}$ & $<0.001^{*}$ & $<0.001 *$ \\
\hline $\begin{array}{l}\text { Co-Morbidity } \\
\text { (Asthma) }\end{array}$ & 0.553 & 0.977 & $0.003 *$ & 0.116 & 0.977 & 0.208 \\
\hline $\begin{array}{l}\text { Allergy Type } \\
\text { (PAR/IAR) }\end{array}$ & 0.322 & 0.444 & $0.042 *$ & 0.653 & 0.735 & 0.188 \\
\hline $\begin{array}{l}\text { Duration of AR } \\
\text { symptoms }\end{array}$ & 0.423 & $<0.001^{*}$ & $0.005^{*}$ & $0.001 *$ & $0.003^{*}$ & $<0.001 *$ \\
\hline
\end{tabular}

* Statistically significant $\mathrm{p}-$ values $(\mathrm{p}<0.05)$

PAR- Perennial Allergic Rhinitis; IAR - Intermittent Allergic Rhinitis 
Table 4: Inter-item Correlation between the Components of the Mini Rhinoconjuctivitis Questionnaire sub-group.

\begin{tabular}{|c|c|c|c|c|c|c|}
\hline & $\begin{array}{l}\text { Activity } \\
\text { limitation } \\
\text { (p -value) }\end{array}$ & $\begin{array}{l}\text { Practical } \\
\text { problems } \\
\text { (p-value) }\end{array}$ & $\begin{array}{l}\text { Nasal } \\
\text { symptoms } \\
\text { (p - value) }\end{array}$ & $\begin{array}{l}\text { Eye } \\
\text { symptoms } \\
\text { (p -value) }\end{array}$ & $\begin{array}{l}\text { Other } \\
\text { symptoms } \\
\text { (p -value) }\end{array}$ & $\begin{array}{l}\text { Total } \\
\text { score } \\
\text { (p -value) }\end{array}$ \\
\hline $\begin{array}{l}\text { Activity } \\
\text { limitation }\end{array}$ & 1 & $\begin{array}{c}0.360 \\
\left(0.003^{*}\right)\end{array}$ & $\begin{array}{c}0.486 \\
(<0.001 *)\end{array}$ & $\begin{array}{c}0.217 \\
(0.080)\end{array}$ & $\begin{array}{c}0.410 \\
(0.001 *)\end{array}$ & $\begin{array}{c}0.675 \\
(<0.001 *)\end{array}$ \\
\hline $\begin{array}{l}\text { Practical } \\
\text { problems }\end{array}$ & $\begin{array}{c}0.360 \\
(0.003 *)\end{array}$ & 1 & $\begin{array}{c}0.585 \\
(<0.001 *)\end{array}$ & $\begin{array}{c}0.381 \\
(0.002 *)\end{array}$ & $\begin{array}{c}0.587 \\
(<0.001 *)\end{array}$ & $\begin{array}{c}0.718 \\
(<0.001 *)\end{array}$ \\
\hline $\begin{array}{l}\text { Nasal } \\
\text { problems }\end{array}$ & $\begin{array}{c}0.486 \\
(<0.001 *)\end{array}$ & $\begin{array}{c}0.585 \\
(<0.001 *)\end{array}$ & 1 & $\begin{array}{c}0.645 \\
\left(<0.001^{*}\right)\end{array}$ & $\begin{array}{c}0.673 \\
(<0.001 *)\end{array}$ & $\begin{array}{c}0.866 \\
(<0.001 *)\end{array}$ \\
\hline $\begin{array}{l}\text { Eye } \\
\text { problems }\end{array}$ & $\begin{array}{c}0.217 \\
(0.080)\end{array}$ & $\begin{array}{c}0.381 \\
(0.002 *)\end{array}$ & $\begin{array}{c}0.645 \\
\left(<0.001^{*}\right)\end{array}$ & 1 & $\begin{array}{c}0.703 \\
\left(<0.001^{*}\right)\end{array}$ & $\begin{array}{c}0.750 \\
(<0.001 *)\end{array}$ \\
\hline $\begin{array}{l}\text { Other } \\
\text { symptoms }\end{array}$ & $\begin{array}{c}0.410 \\
\left(0.001^{*}\right)\end{array}$ & $\begin{array}{c}0.587 \\
(<0.001 *)\end{array}$ & $\begin{array}{c}0.673 \\
(<0.001 *)\end{array}$ & $\begin{array}{c}0.703 \\
(<0.001 *)\end{array}$ & 1 & $\begin{array}{c}0.868 \\
\left(<0.001^{*}\right)\end{array}$ \\
\hline $\begin{array}{l}\text { Total } \\
\text { score }\end{array}$ & $\begin{array}{c}0.675 \\
(<0.001 *)\end{array}$ & $\begin{array}{c}0.718 \\
(<0.001 *)\end{array}$ & $\begin{array}{c}0.866 \\
\left(<0.001^{*}\right)\end{array}$ & $\begin{array}{c}0.750 \\
(<0.001 *)\end{array}$ & $\begin{array}{c}0.868 \\
(<0.001 *)\end{array}$ & 1 \\
\hline
\end{tabular}

* Statistically significant $\mathrm{p}-$ values $(\mathrm{p}<0.05)$

About $70 \%$ of the patients with AR (46/66) had mini-RQLQ values of 3 to 5 TSS scores (moderately troubled to quite a bit troubled) for quantifying the health-related quality of life (Table 2). Significant p-values were obtained for gender, marital status, number of dependents, senatorial districts, residential area and duration of symptoms ( $p=0.016,0.016$, $0.012,0.001,<0.001$ and $<0.001$ respectively). Senatorial districts, residential area and 
duration of symptoms were noted to have significant p-values for almost all the 5 components of the mini-RQLQ (Table 3).

Essentially all the various components of the mini-RQLQ correlated significantly with TSS values $(p<0.001)$ (Table 4). Nasal and other symptoms are more related to the Total Symptom Score (TSS) than any other components $(r=0.866$ and 0.868 respectively). The highest correlation between the components of the mini-RQLQ existed between eye problems and other symptoms $(r=0.703)$.

\section{Discussion}

The study noted that allergic rhinitis had a significant effect on the health-related quality of life of individuals diagnosed as suffering from allergic rhinitis as compared with matched controls in Kwara state, Nigeria. The major contributory factors to worsening of healthrelated quality of life of the individuals with allergic rhinitis were found to be respondent's residential area and the duration of the respondent's allergic symptoms. Nasal symptoms as well as the other symptoms were noted to be most related to Total Symptom Score (TSS) based on the mini Rhinoconjuctivitis Quality of Life (mini-RQLQ) questionnaire.

There was a female preponderance found in this study (M: F ratio, 1:1.2). This was in keeping with the findings of a study carried out in North-Central Nigeria ${ }^{12}$ (73\% female preponderance) and Turkey, where the male to female ratio was $1: 1.1{ }^{13}$ Some other studies have however reported a larger male to female ratio. ${ }^{14-16}$ The difference may be a representation of the findings in the general population where, according to the 2006 National Census figures in Nigeria, there is a slight female preponderance. ${ }^{17}$ Total Symptom Score (TSS) for allergic patients using the mini-RQLQ was $3.37 \pm 0.9$ with a male value of 3.61 \pm 1.0 and female value of $3.16 \pm 0.8$. The TSS refers to the total overall average of the 5 parameters of the mini-RQLQ (namely, activity limitation, practical problems, nasal symptoms, eye symptoms and other symptoms). The finding is significantly higher than that of $1.54 \pm 1.06$ reported by Small et al, ${ }^{18}$ from a cross-sectional cohort study amongst primary care physicians and allergy specialists in France, Germany and Spain. The difference might be due to the involvement of both perennial and intermittent AR patients in the index study. Also the significant difference might have been caused by the community based nature of this present study. 
The duration of AR symptoms was found to be significant in all mini-RQLQ components ( $p$ $<0.001)$ except for activity limitation component $(\mathrm{p}=0.423)$. While the type of allergy (either persistent or intermittent allergic rhinitis) was only significant for nasal symptoms ( $p$ $=0.042$ ), but not for other aspects of the mini-RQLQ components. The severity and duration of rhinitis has been reported to have an impact on the quality of life and visual analogue scores (VAS) of AR patients. ${ }^{19}$ However, the study carried out by Bousquet et al, ${ }^{20}$ reported that only severity of AR symptoms and not its duration, affected the clinical profile of the patients. This study noted that $80 \%$ of the patients with more severe forms reported an impairment in activity when compared with $40 \%$ with mild forms.

The presence of co-morbidities in the AR patients (Asthma was the major one studied), was only significant on the nasal symptoms $(\mathrm{p}=0.003)$ but not for the other aspects of the miniRQLQ. This finding is similar to a study evaluating the impact of AR on the quality of life of asthmatics in Turkey. ${ }^{21}$ The study involved 232 patients with AR, 40 patients with asthma and 44 patients with both diseases and concluded that the impact of AR on asthma only played a minor role. This finding was further corroborated by the findings of Leynaert et al, ${ }^{22}$ whose study showed that asthma was not found to significantly impair the quality life of AR patients in terms of mental disability and well-being. However, contrary to these findings Aydemir et $\mathrm{al}^{23}{ }^{23}$ in a comparative hospital-based study, noted that respiratory allergic diseases had detrimental effects on quality of life. Thus, due to the similarity in the pathophysiology of the two conditions, it has been corroborated that AR treatment reduces the incidence and severity of asthma. ${ }^{24}$ In fact, Maspero $\mathrm{J}$ et $\mathrm{al}^{25}$ in the study involving AR patients in Western Europe and the United States, reported a significant number of AR patients with concomitant asthma, hence justifying the inclusion of asthma in formulating AR control.

The senatorial districts and the residential area where the respondents with significant miniRQLQ findings reside (in almost all 5 domains) appeared to be a major contributory factor to the HRQoL ( $\mathrm{p}=<0.001$ to 0.007 ). This may be related to the availability of and accessibility to healthcare in the state. Kwara central senatorial district had the largest concentration of healthcare services (primary, secondary and tertiary), and had the lowest amount of AR patients. Apart from the public hospitals, private hospitals also tend to be concentrated within the Kwara central district. Abodunrin et $\mathrm{al}^{26}$ in a study carried out in Kwara state on the preferred choice of healthcare facilities among adult residents, opined that due to the availability of quick service and drugs, private hospitals were preferred to public ones and that higher levels of health care were preferred to primary ones. The study also noted that 
gender, occupation and city area of residence were all associated with the preferred choice of health care.

One of the most cogent findings in the study was that most of the components of the miniRQLQ correlated significantly with TSS values $(\mathrm{p}<0.001)$. Nasal and other symptoms were noted to be more related to the Total Symptom Score (TSS) than any other components $(r=$ 0.866 and 0.868 respectively). This suggests that while all components of mini-RQLQ are important correlates of overall symptom, nasal as well as other symptoms were better correlates or determinants. Hence, nasal symptom component of mini-RQLQ questionnaire may then be used for preliminary assessment of RQLQ. It was noted that an increase in the level of nasal symptoms resulted in an increase in the overall symptom score.

The main limitation of this study was the fact that there was no re-evaluation of the miniRQLQ questionnaire in the respondents after treatment. Also the study did not administer any AR medication as part of the research protocol or evaluate its effect on the patient's quality of life. This is because apart from the instrument identifying the HRQoL, it also has the ability to detect changes over time and the efficacy of treatment given. ${ }^{27}$ However that was not the aim of this study. Further research may therefore be required to evaluate whether changes (improvement or deterioration) in the quality of life of AR patients occurs with improvement in the various identifiable contributory factors.

\section{Conclusion / Significance}

Allergic Rhinitis had appreciable impact on the health-related quality of life of the subjects with AR who participated in this study. Gender, marital status, senatorial districts, residential area and duration of symptoms were major identifiable contributory factors to the patient's wellbeing.

\section{Acknowledgement}

The authors wish to acknowledge the contributions of Prof T.M Akande, Consultant Epidemiologist and Community health physician, Department of Epidemiology and Community Health, College of Health Sciences, University of Ilorin and University of Ilorin Teaching Hospital, Ilorin, Nigeria, who assisted in the review of the manuscript. Also acknowledged are the contributions of, Dr Oyinloye I.F, Dr Adedayo A.G, Dr Ogundoyin 
O.A, Dr Okonobo-Ayeke J.O (Residents, Department of Otorhinolaryngology, Ladoke Akintola University of Technology (LAUTECH) Teaching Hospital, Ogbomoso, Nigeria) who assisted with data collection and collation.

\section{Conflict of Interest}

The authors declare that there are no conflicts of interest in carrying out this research.

\section{REFERENCES}

1. Ologe FE, Adebola SO, Dunmade AD, Adeniji KA, Oyejola BA. Symptom score for allergic rhinitis Otolaryngology-Head and Neck Surgery2013;148(4):557 - 63.

2. Bousquet J, Khaltaev N, Cruz AA, Denburg J, Fokkens WJ, Togias A, et al. Allergic Rhinitis and its Impact on Asthma (ARIA) 2008 Update (in collaboration with the World Health Organization, GA²LEN). Allergy2008;63(s86):8 - 160.

3. McHorney CA. Health status assessment methods for adults: past accomplishments and future challenges. Annu Rev Public Health Aff (Millwood)1999;20:309 - 35.

4. Ozdoganoglu T, Songu M, Inancli HM. Quality of life in allergic rhinitis. Ther Adv Respir Dis 2012;6(1):25 - 39.

5. Juniper EF. Measuring health-related quality of life in rhinitis. J Allerg Clin Immunol (Paris)1997;99(2):S742 - 49.

6. Stewart AL, Hays R, Ware JE. The MOS short-form general health survey. Reliability and validity in a patient population. Med Care1988;26:724 - 32.

7. Hunt SM, Mckenna SP, McEwen J, Backett EM, Williams J, Papp E. A quantitative approach to perceived health status: a validation study. J Epidemiol Community Health1980;34:281 - 6.

8. Juniper EF, Thompson AK, Ferrie PJ, Roberts JN. Development and validation of the mini Rhinoconjunctivitis Quality of Life Questionnaire. Clin Exp Allergy2000 Jan;30(1):132-40.

9. Juniper EF, Thompson AK, Ferrie PJ, Roberts JN. Validation of the standardized version of the Rhinoconjuctivitis Quality of Life questionnaire. J Allerg Clin Immunol (Paris)1999;104(2, Part 1):364 - 9.

10. Preliminary report, National Population Commission 2006. . Census News, 2007;61:16.

11. Annesi-Maesano I, Didier A, Klossek M, Chanal I, Moreau D, Bousquet J. The score for allergic rhinitis (SFAR): a simple and valid assesment method in population studies. Allergy2002;57:107 - 14.

12. Olusesi AD, Said MA, Amodu EJ. A correlation of symptomatology with nasal smear eosinophilia in non-infectious chronic rhinitis preliminary report. Niger J Clin Pract2007 Sep;10(3):238-42.

13. Songu M, Ural A, Erdogmus N, Bal C , Score For Allergic Rhinitis (SFAR) study in Turkey. Otolaryngol Head Neck Surg2010;143(2 s):139 - 40.

14. Takwoingi Y, Akang E, Nwaorgu G, Nwawolo C. Comparing nasal secretion eosinophil count with skin sensitivity test in allergic rhinitis in Ibadan, Nigeria. Acta Otolaryngol2003 Dec;123(9):1070-4.

15. Piau JP, Massot C, Moreau D, Ait-Khaled N, Bouayad Z, et al. Assessing allergic rhinitis in developing countries. Int J Tuberc Lung Dis2010;14(4):506 - 12.

16. Lasisi AO, Lawal HO, Ogun GO, Oluwasola A, Odubanjo MO, et al. Correlation Between Eosinophilia and Nasal Features in Allergic Rhinosinusitis: A Pilot Study. Journal of Asthma and Allergy Educators2010;1:219 - 22. 
17. http://www.who.int/whosis/en/ Nigeria, World Health Organisation (WHO) Report, 2006. Country Health System Fact Sheet. Accessed June 6, 2014.

18. Small M, Piercy J, Demoly P, Marsden H. Burden of illness and quality of life in patients being treated for seasonal allergic rhinitis: a cohort survey. Clinical and Translational Allergy2013;3(33):1 - 9.

19. Bousquet $\mathrm{P}$, Demoly $\mathrm{P}$, Devillier $\mathrm{P}$, Mesbah $\mathrm{K}$, Bousquet J. Impact of Allergic Rhinitis symptoms on quality of life in primary care. Int Arch Allergy Immunol2013;160:393 - 400.

20. Bousquet J, Neukirch F, Bousquet PJ, Gehano P, Klossek JM, Le Gal M, et al. Severity and impairment of allergic rhinitis in patients consulting in primary care. J Allerg Clin Immunol (Paris)2006;117(1):158 - 62.

21. Kalpaklioglu AF, Baccioglu A. Evaluation of quality of life: Impact of allergic rhinitis on asthma. J Invest Allergol Clin Immunol2008;18(3):168 - 73.

22. Leynaert B, Neukirch C, Liard R, Bousquet J, Neukirch F. Quality of life in allergic rhinitis and asthma. A population-based study of young adults. Am J Respir Crit Care Med2000;162(4 Pt 1):1391 - 6.

23. Aydemir O, Sakar A, Kirmar C, Taskin EO, Sepit L. Quality of Life in Asthma and Allergic Rhinitis: A Hospital-Based Comparative Study. Turkish Respiratory Journal2006;7(3):101 -4.

24. Crystal-Peters J, Neslusan C, Crown WH, Torres A. Treating allergic rhinitis in patients with comorbid asthma: the risk of asthma-related hospitalizations and emergency department visits. J Allerg Clin Immunol (Paris)2002;109(1):57 - 62.

25. Maspero J, Lee BW, Katelaris CH, Potter PC, Cingi C, Lopatin A, et al. Quality of life and control of allergic rhinitis in patients from regions beyond western Europe and the United States. Clin Exp Allergy2012;42:1684 - 96.

26. Abodunrin OL, Bamidele JO, Olugbenga-Bello Al, Parakoyi DB. Preferred choice of health facilities for healthcare among adult residents in Ilorin metropolis, Kwara state, Nigeria. International journal of Health research2010;3(2):79 - 86.

27. Juniper EF, Stahl E, Doty RL, Simons FE, Allen DB, Howarth PH. Clinical outcomes and adverse effect monitoring in allergic rhinitis. J Allerg Clin Immunol (Paris)2005;115(S390 - 413). 